\title{
Analysis of heavy metals during composting of the tannery sludge using physicochemical and spectroscopic techniques
}

\begin{abstract}
The major limitation of direct application of tannery sludge compost in agriculture is the total heavy metal contents and their bioavailability to the soilï plant system. This study focused on the heavy metal characterization and the influence of changing the physicochemical properties of the medium throughout the composting on the concentrations, bioavailability or chemical forms of $\mathrm{Cr}, \mathrm{Cu}, \mathrm{Zn}, \mathrm{Pb}$ and $\mathrm{Cd}$ in tannery sludge. The study shows that throughout the 60 days of composting, physicochemical analysis and Fourier-transformed infrared (FTIR) spectroscopic characterization show that all parameters elaborated and reached relatively stable levels reflecting the stability and maturity of the final product, and revealed the biodegradation of components that can be easily assimilated by microorganism. The $\mathrm{C} / \mathrm{N}$ ratio reaches the optimal range of stable compost; inorganic nitrogen is transformed into stable organic forms. The total concentration of $\mathrm{Cr}, \mathrm{Zn}, \mathrm{Cu}, \mathrm{Pb}$ and $\mathrm{Cd}$ is very low rendering final compost acceptable for agricultural use. The germination index for both Chinese cabbage and lettuce was $97 \%$ after 60 days of composting, showing that the final compost was not phytotoxic. Furthermore, in using a sequential extraction method in sludge compost at different phases of treatment, a less than $2 \%$ of metals bound to bioavailable fractions Xï $(\mathrm{KNO} 3+\mathrm{H} 2 \mathrm{O})$. A large proportion of the heavy metals were associated to the residual fraction $(75 \mathrm{I} 85 \%)$ and more resistant fractions to extraction Xï NaOH, Xï EDTA, XÏ HNO3 (15ï 25\%). Mobile fractions of metals are poorly predictable from the total content. Bioavailability of all fractions of elements tends to decrease.
\end{abstract}

Keyword: Tannery; Sludge; Composting; Heavy metals; Bioavailability 